\title{
Coenzyme A
}

National Cancer Institute

\section{Source}

National Cancer Institute. Coenzyme A. NCI Thesaurus. Code C384.

A coenzyme containing pantothenic acid, adenosine 3-phosphate 5-pyrophosphate, and cysteamine; involved in the transfer of acyl groups, notably in transacetylations. 